\title{
Retinal Synaptic Arrays: Continuing Development in the Adult Goldfish
}

\author{
LESLIE J. FISHER ${ }^{1}$ AND STEPHEN S. EASTER, JR. ${ }^{2}$ \\ ${ }^{1}$ Department of Anatomy and ${ }^{2}$ Division of Biological Sciences, University of Michigan, \\ Ann Arbor, Michigan 48109
}

\begin{abstract}
We report a light-and electron-microscopic examination of the inner plexiform layer of the central retina of young (c. 1 year) and old (3-4 year) goldfish. There were no new neurons added to this region during the growth period. Nonetheless, there were substantially more synapses (per cell, per $\mathrm{mm}^{2}$, or per degree ${ }^{2}$ ) in the older retinas. This result is discussed in the contexts of retinal function and neural development.
\end{abstract}

The retinas of vertebrates grow by adding new neurons. In mammals and birds, this neurogenesis stops before, or soon after, the eye begins to function (Sidman, '61; Fujita and Horii, '63; Kahn, '74), but in fish and amphibians, retinal growth continues well beyond that time (Müller, '52; Hollyfield, '68; Gaze and Watson, '68; Chung et al., '75; Johns and Easter, '77; Easter et al., '77; Johns, '77). The numbers are quite impressive; a small goldfish, $4 \mathrm{~cm}$ long and less than a year old, has about 3 million retinal cells, while a $23 \mathrm{~cm}$ fish, four to five years old, has about $20 \mathrm{mil}$ lion in a very much larger retina. These new cells are all added at the retinal margin (Johns, '77), with the result that the oldest neurons are generally located centrally, the younger ones toward the periphery (Müller, '52; Johns, '77; Morest, '70). The marginal retina is therefore analogous to embryonic tissue in other animals, and, not surprisingly, shows many of the same features, such as immature photoreceptor outer segments (Müller, '52).

Concurrently with this marginal neurogenesis, the older central retina is also changing. Radially, it thickens slightly. Tangentially, the cells move apart, but not proportionately in all layers, with the result that the ratios of various cell types differ in large and small retinas (Johns and Easter, '77). The magnification factor, defined as the number of micrometers on the retinal surface per degree in the visual field, increases (Easter et al., '77). If the number of synapses in the central retina remained constant, an increase in retinal thickness would be expected to lower the number of synapses per unit volume. If, however, new synapses appeared, a different result would be predicted. The work reported below was prompted by the question: Are synapses added to the central retina as it grows?

With the electron microscope, we have examined quantitatively the inner plexiform layer in the central retinas of young and old goldfish. In this layer, the neurons of the inner nuclear layer (bipolar, amacrine, and interplexiform cells) contact each other and the ganglion cells. Two types of synapse have been identified: ribbon and conventional. The former is so called because the presynaptic terminal (from a bipolar cell) contains a ribbon-shaped organelle in addition to synaptic vesicles (fig. 1A); this terminal contacts amacrine and ganglion cell processes (Dowling and Boycott, '66; Raviola and Raviola, '67; Witkovsky and Dowling, '69). The conventional synapse lacks a ribbon (fig. 1B); its presynaptic terminal may come from an amacrine cell (Dowling and Boycott, '66; Raviola and Raviola, '67; Witkovsky and Dowling, '69), or an interplexiform cell (Dowling et al., '76), or a neuron in the brain with an efferent fiber to the retina (Witkovsky, '71; Sandeman and Rosenthal, '74). In addition, a bipolar cell if sectioned in such a way that the ribbon was not included, could erroneously be identified as containing a conventional synapse. Of these four possibilities, the amacrine is believed to be the most numerous. The postsynaptic process involved in a conventional synapse may belong to an amacrine or a bipolar or an interplexiform or a ganglion cell (Dowling and Boycott, '66; Raviola and Raviola, '67; Witkovsky and Dowling, '69; Dowling et al., '76).

\section{METHODS}

Goldfish (Carassius auratus, Common 

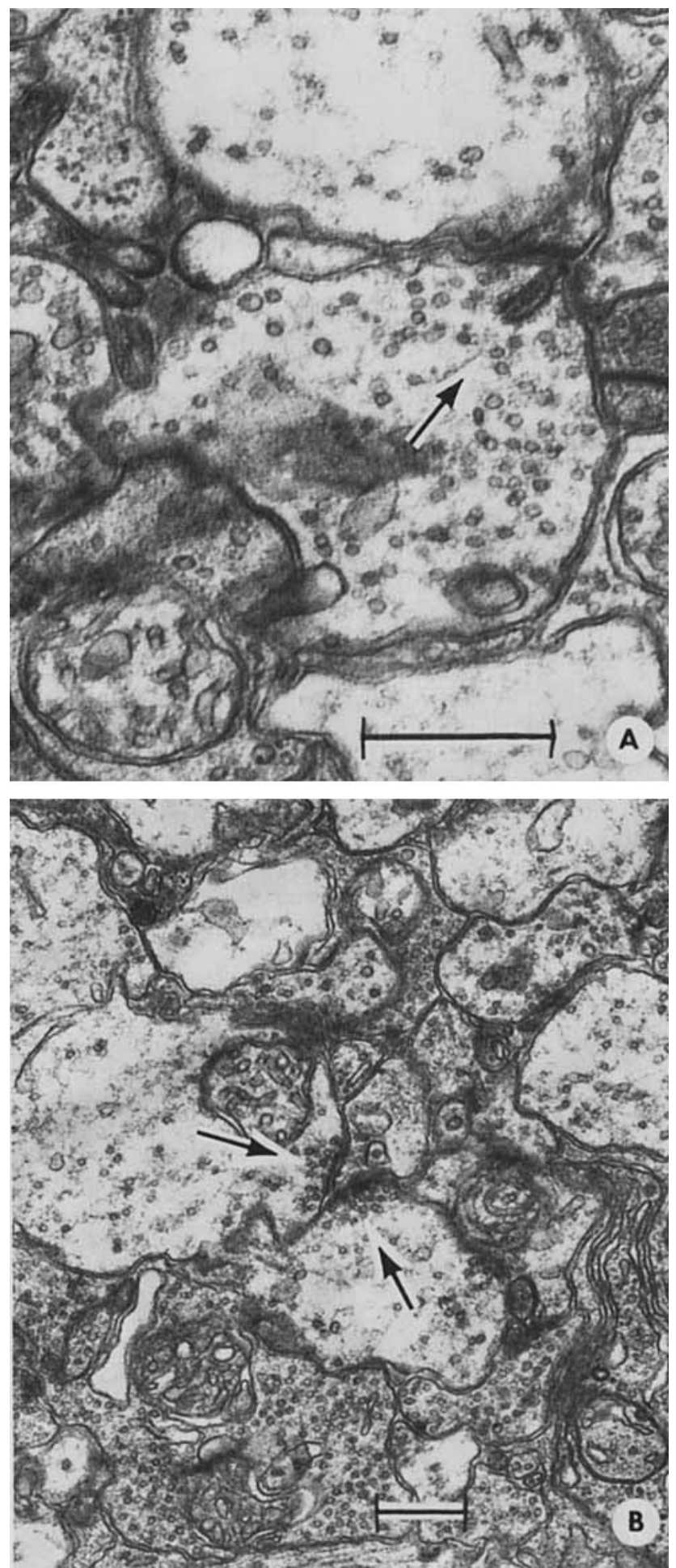

Fig. 1 Electron micrographs (A) ribbon synapse (arrow), (B) conventional synapses (arrows). Calibration bars $=0.5 \mu \mathrm{m}$ 
strain) were obtained commercially. Six fish, three small and three large, were used. The two groups differed in age (less than one year vs three to four years), body length ( $5.4 \pm 0.6$ $\mathrm{cm}$ vs $15.5 \pm 0.6 \mathrm{~cm}$, tip to tip, mean \pm S.D.) and lens diameter $(1.62 \pm 0.12 \mathrm{~mm}$ vs $2.90 \pm$ $0.12 \mathrm{~mm}$, mean \pm S.D.). We assume that the small fish resembled an earlier stage of the large ones, so that whenever we compare the two groups we are assessing the effects of growth.

The fish were anesthetized, both eyes removed, and the lens, iris and cornea trimmed away. The lens diameter was measured for cal. culation of the retinal magnification factor at the level of the middle of the inner plexiform layer (Easter et al., '77). The ventral edge of the eye cup was marked for purposes of orientation and the tissue was pre-fixed in buffered aldehydes, post-fixed in buffered osmic acid, stained en bloc with uranyl acetate, and embedded in Epon. All eyes were sectioned in the horizontal plane and all samples taken from a region $200-500 \mu \mathrm{m}$ rostral or caudal to the optic disc. Semithin radial sections $(1 \mu \mathrm{m}$ thick) stained with methylene blue were viewed light microscopically. Nuclei in the inner nuclear and ganglion cell layers were counted and their diameters measured. The thicknesses of the inner nuclear and inner plexiform layers were measured. The ganglion cell layer, only one cell thick, was not measured. Thin radial sections $(60-90 \mathrm{~nm})$ through the inner plexiform layer were stained with uranyl acetate and lead citrate and viewed in the electron microscope. In each retina, one or two sets of electron micrographs were taken of contiguous regions covering about $1,000 \mu \mathrm{m}^{2}$ from the inner nuclear to the ganglion cell layer. Prints of these negatives (final magnification $26,000 \times-27,000 \times$ ) were then used to construct photomosaics which were scored for conventional and ribbon synapses (Dubin, '70; Fisher, '76). Typically each photomosaic yielded relatively few ribbon synapses (1-10), and many more conventionals (30-50). To increase the sampling of ribbons, an additional set of 12 mosaics, one per retina, each covering about $4,000 \mu \mathrm{m}^{2}$, final magnification $12,000 \times$, was prepared and scored for ribbons only.

\section{RESULTS}

All synaptic contacts were measured, and the mean lengths (Dubin, '70; Fisher, '76) of both kinds of synapse were determined. The mean length of the conventionals was the same in both large and small fish; so too was the mean length of the ribbons. We infer that, as the retina grew, the size of the individual synapses did not change, on the average.

Light micrographs were analyzed using the Abercrombie correction (Abercrombie, '46) for ganglion cell nuclei and stereological sampling (Weibel, '69) for inner nuclei. Electron micrographs were analyzed using Dubin's modified Abercrombie correction (Dubin, '70). These procedures generated several quantitative descriptors listed below:

(1) Numerical density: the number of elements (nuclei or synaptic contacts) per unit volume $\left(1,000 \mu \mathrm{m}^{3}\right)$ of the layer in question (e.g., inner nuclear or inner plexiform).

(2) Retinal planimetric density: the number of elements per unit of retinal surface $\left(1,000 \mu \mathrm{m}^{2}\right)$, as viewed from the lens. The surface considered here is orthogonal to the plane of section of the micrographs, and passes through the middle of the layer in question (e.g., inner nuclear, inner plexiform, or ganglion cell). In solid geometric terms, the retinal planimetric density is therefore the number of elements within a layer which project onto a unit surface in the layer. This number was obtained by multiplying the numerical density by the thickness of the layer in question (inner plexiform: $27 \mu \mathrm{m}$ in the small fish, 34 $\mu \mathrm{m}$ in the large; inner nuclear: $36 \mu \mathrm{m}$, small; $39 \mu \mathrm{m}$, large). For instance, the retinal planimetric density of conventional synapses was obtained by multiplying the numerical density of conventionals by the thickness of the inner plexiform layer.

(3) Visual planimetric density: the number of elements per unit of retinal surface, also as viewed from the lens, but measured in (visual degrees) ${ }^{2}$. This descriptor was obtained by multiplying the retinal planimetric density by (retinal magnification factor) ${ }^{2 / 1}, 000$ (retinal magnification factor: $31 \mu \mathrm{m} /$ degree for the small fish, $56 \mu \mathrm{m} /$ degree for the large). The planimetric densities are measures of the "synaptic grain" of the retina, to use an analogy with photographic film.

(4) Synapses/nucleus: the mean number of synapses per nucleus, obtained by dividing retinal planimetric density of synapses by retinal planimetric density of nuclei.

The data are summarized in figures 2 and 3 , ten bar graphs which compare small and large fish with respect to these four descriptors. In all cases, computations were carried out for 


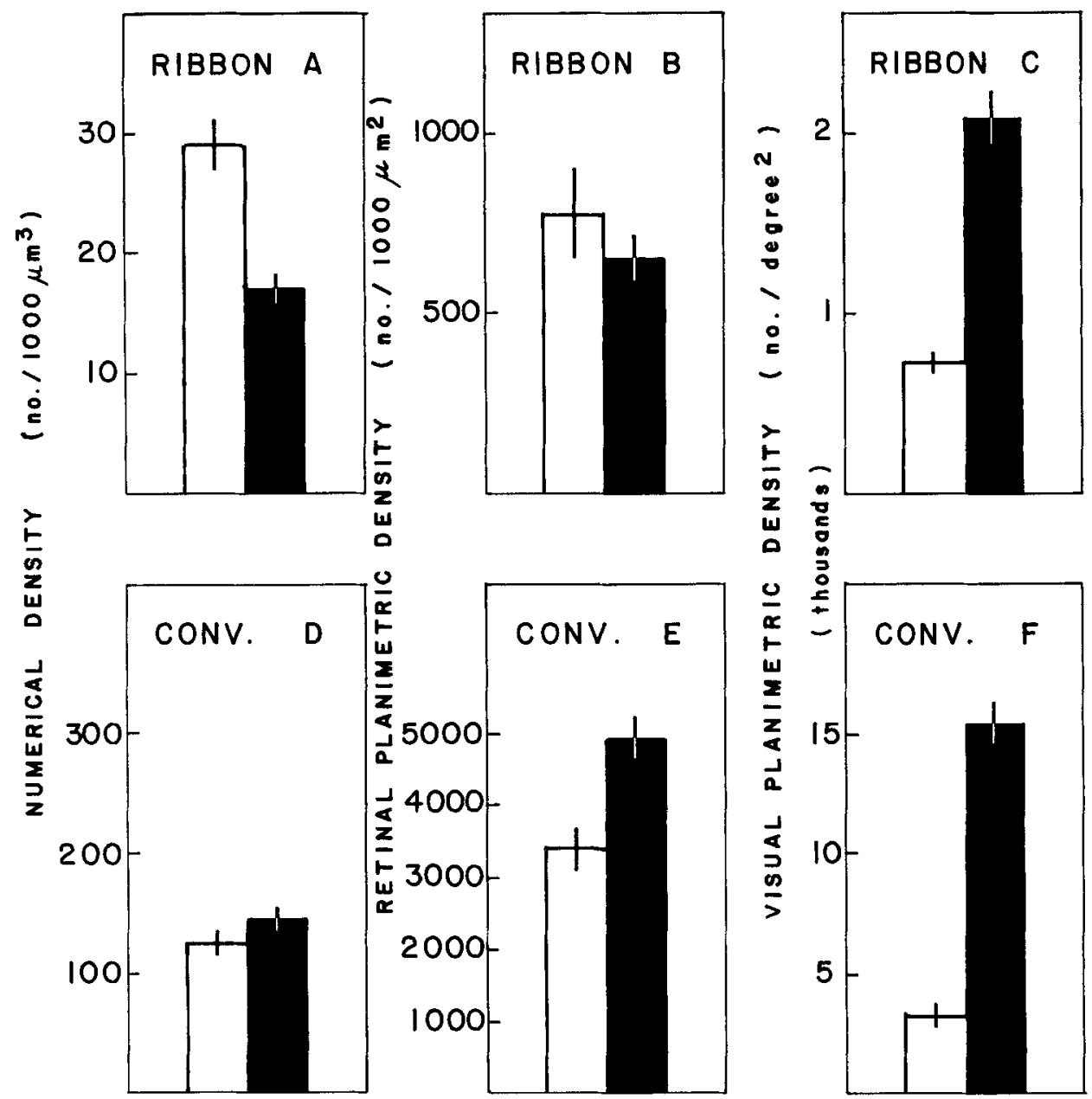

Fig. 2 (A) and (D) numerical densities, (B) and (E) retinal planimetric densities, (C) and (F) visual planimetric densities of ribbon and conventional synapses, respectively. Light columns: small fish. Dark columns: large fish. Error bars: \pm 1 SEM. Densities for small and large fish were compared using Student's ttest (Fisher, '46); $p<0.01$ for A, C, E, and F; $>0.1$ for B and D.

individual photomosaics, and the means $( \pm$ SEM) were plotted.

The numerical density of ribbon synapses decreased with growth, as shown in figure $2 \mathrm{~A}$. The retinal planimetric density of ribbons remained roughly constant (fig. $2 \mathrm{~B}$ ). The visual planimetric density of ribbons (fig. 2C) more than doubled owing to the increased retinal magnification factor of the larger eyes.

Figure 2D shows that the numerical density of conventional synapses did not change. The retinal planimetric density of conventionals was slightly higher in the big fish (fig. 2E), but the greatest change was in the visual planimetric density, which increased roughly 5 -fold, as shown in figure $2 \mathrm{~F}$.

The ratio - retinal planimetric density of synapses in the inner plexiform layer/retinal planimetric density of nuclei in the inner nuclear layer - increased with growth, as figures $3 \mathrm{~A}$ and $\mathrm{B}$ show. This demonstration that the mean number of synapses per nucleus increased does not necessarily imply that all cells in the larger fish have more synapses. The denominator $\left(78 / 1,000 \mu \mathrm{m}^{2}\right.$ in the small fish, $35 / 1,000 \mu \mathrm{m}^{2}$ in the large) refers to $\mathrm{nu}$ clei of several types: bipolar, amacrine, interplexiform, and perhaps some undifferenti- 

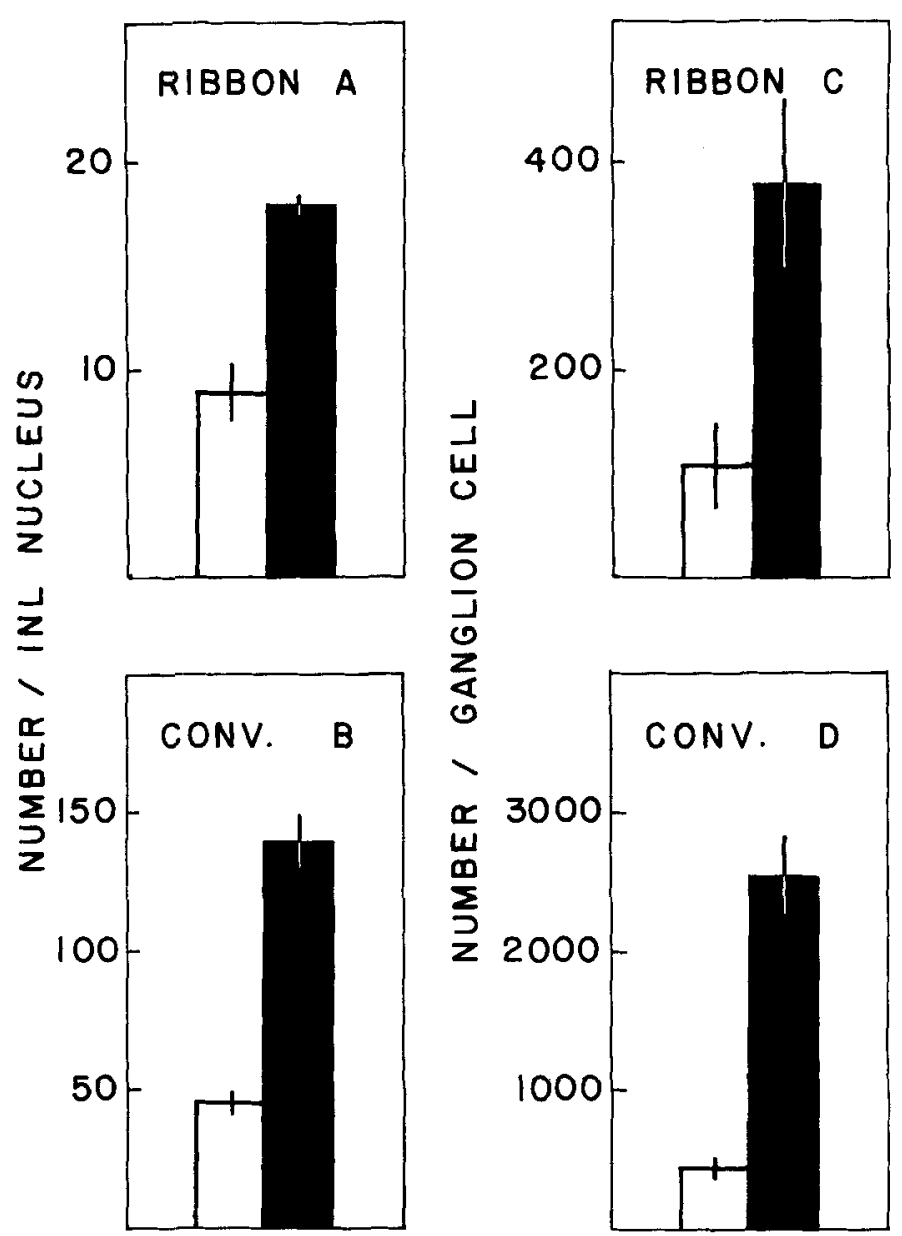

Fig. 3 The number of synapses in the inner plexiform layer per nucleus in the inner nuclear layer ( $A$ and B) or per nucleus in the ganglion cell layer (C and D). Light columns: small fish. Dark columns: large fish. Error bars: \pm 1 SEM.

ated cells. Horizontal and Müller cells were not included, as their nuclei are easily recognized. The increased ratio might have resulted from any or all of the following changes:

(1) Individual neurons which made synapses in the young retinas made more of them in the older ones.

(2) Cells which made no synapses in the young retinas made them in the older ones. This implies a transformation of neuroblasts into neurons. As in the first alternative, these cells might have their nuclei in the inner nuclear layer or in the brain.

(3) Inner nuclear layer cells which made relatively few or no synapses in the young retinas have disappeared from the older ones. Cell death is well documented in other developing nervous systems (Cowan, '73; Glucksmann, '65) and may occur in the adult goldfish inner nuclear layer (Johns, '77). However, cell loss cannot be greater than about $50 \%$ (Johns, '77) which would halve the denominator and double the ratio. Figure 3 shows that the ratio has more than doubled for the conventionals. Therefore, cell death cannot be the only process involved here.

Finally, the ratio - retinal planimetric density of synapses in the inner plexiform layer/ retinal planimetric density of ganglion cell nuclei - also increased with growth, as is illustrated in figures $3 C$ and $D$. Since we cannot recognize a ganglion cell dendrite, we cannot 
estimate what fraction of these synapses involved ganglion cells directly. But the increase suggests that, as the retina grew, the ganglion cells (retinal planimetric density: $7.9 / 1,000 \mu \mathrm{m}^{2}$ in the small fish, $1.9 / 1,000 \mu \mathrm{m}^{2}$ in the large) were served by a more complex synaptic network.

In summary, although no new cells have been added to the central retina (Johns, '77), its inner plexiform layer has changed markedly with age. The synaptic grain has become much finer, especially with respect to conventional synapses. And, on the average, the number of synapses per cell has increased substantially.

\section{DISCUSSION}

Considered in the context of retinal function, it seemy reasonable to assume that a higher visual planimetric density of synapses enables the retina to analyze the visual image more thoroughly. Therefore, these results sug. gest that the retina of the larger goldfish is a better analyst of the visual image than the smaller. In support of this idea, we note that big fish have higher visual acuity than their smaller conspecifics (Baerends et al., '60). Although this behavioral change was attributed to finer photoreceptor grain (increased visual planimetric density of receptors), the neural basis of visual acuity is not well understood. The idea that the spacing of receptors should entirely account for visual acuity is made unlikely by numerous recent demonstrations that photoreceptors are coupled to one another (Baylor et al., '71; Custer, '73; Raviola and Gilula, '73; Witkovsky et al.,'74; Copenhagen and Owen, '76; Fain et al.,'76). We suggest that the finer synaptic grain of the older fish retinas may also contribute to acuity.

Considered in the context of cellular development, the growth and differentiation of the goldfish inner plexiform layer can be directly compared to the homologous process in the two other vertebrates which have been examined: an amphibian, the larval Xenopus laevis (Fisher, '76), and a mammal, the neonatal Mus musculus (Fisher, '75). In all three cases, the numerical density of conventional synapses is maintained constant as the animal ages. In Xenopus and goldfish, this constancy holds even as the retina grows. For ribbon synapses, in contrast, the retinal planimetric density is constant. Restated, there is a constant ribbon synaptic input to a given retinal area, and a constant conven- tional synaptic complement within a given volume. We can offer no compelling reasons why these two descriptors should be maintained constant, but we speculate that the constant numerical density of conventionals might represent a compromise between two (hypothetical) conflicting effects. On the one hand, a higher density of synapses might improve the neural image-processing. On the other hand, it seems likely that synapses can not be spaced arbitrarily closely and still continue to function effectively. One synapse might interact adversely with a very close neighbor in any of several ways. For instance, the synaptic transmitter might diffuse beyond its local zone to affect the post synaptic membrane of the neighbor. Or the currents in one synapse might deplete the nearby extracellular fluid of ions essential to the function of the neighbor. Perhaps the numerical density which we have observed represents the highest density consistent with synaptic independence.

The evidence that synapses are added to the central arimplies that the adult fish retina is in fact a developing nervous system. This has long been suspected from the observation that the numbers of cells increase steadily (Müller, '52). But the events in the central retina have not previously been considered, nor could they have been, without an ultrastructural analysis. The surprising conclusion that synaptogenesis continues even as the eye functions suggests an expanded role for the fish retina in future studies of growth, development, and plasticity.

\section{ACKNOWLEDGMENTS}

This work was supported by research grants from The United States Public Health Service (EY-01288 to L. J. F., EY-00168 to S. S. E.). We thank Doctor James W. Hinds for his useful comments on a preliminary draft.

\section{LITERATURE CITED}

Abercrombie, M. 1946 Estimation of nuclear population from microtome section. Anat. Rec., 94: 239-247.

Baerends, G. P., B. E. Bennema and A. A. Vogelzang 1960 Uber die Änderund der Sehschärfe mit dem Wachstum bei Aequidens portalegrensis (Hensel) (Pisces, Cichlidae). Zool. Jahrb. Abt. Syst., 88: 67-78.

Baylor, D. A., M. G. F. Fuortes and P. M. O'Bryan 1971 Receptive fields of cones in the retina of the turtle. $J$ Physiol., 214: 265-294.

Chung, S. H., R. V. Stirling and R. M. Gaze 1975 The structural and functional development of the retina in larval Xenopus. J. Embryol. Exp. Morph., 33: 915-940.

Copenhagen, D. R., and W. G. Owen 1976 Coupling between 
rod photoreceptors in a vertebrate retina. Nature, 260 : 57-59.

Cowan, W. M. 1973 Neuronal death as a regulative mechanism in the control of cell number in the nervous system. In: Development and Aging in the Nervous System. M. Rockstein, ed. Academic Press, New York, pp 19-41.

Custer, N. V. 1973 Structurally specialized contacts between the photoreceptors of the retina of the axolotl. J. Comp. Neur., 151: 35-56.

Dowling, J. E., and B. B. Boycott 1966 Organization of the primate retina: electron microscopy. Proc. R. Soc. B., 166. 80-111.

Dowling, J. E., B. Ehinger and W. L. Hedden 1976 The interplexiform cell: a new type of retinal neuron. Invest. Opthal., 15: 916-926.

Dubin, M. W. 1970 The inner plexiform layer of the vertebrate retina: a quantitative and comparative electron microscopic analysis. J. Comp. Neur., 140: 479-506.

Easter, S. S., P. R. Johns and L. R. Baumann 1977 Growth of the adult goldfish eye - I: Optics. Vision Res., 17: 469-477.

Fain, G. L., G. H. Gold and J. E. Dowling 1976 Receptor cou pling in the toad retina. Cold Spring Harbor Symposia on Quantitative Biology, 40: 547-561.

Fisher, L. J. 1975 Developing synapse sets in the differentiating mouse retina. Neurosci. Abst., 1: 96.

1976 Synaptic arrays of the inner plexiform layer in the developing retina of Xenopus. Develop. Biol., 50: $402-412$

Fisher, R. A. 1946 Statistical Methods for Research Workers. Tenth ed. Oliver and Boyd, Edinburgh, pp. 114-128.

Fujita, S., and M. Horii 1963 Analysis of cytogenesis in chick retina by tritiated thymidine autoradiography. Arch. Histol. Jap., 23: 359-366.

Gaze, R. M., and W. E. Watson 1968 Cell division and migration in the brain after optic nerve lesions. In: Growth of the Nervous System. Ciba Foundation Symposium 13. G. E. W. Wolstenholme and M. O'Connor, eds. Churchill, London, pp. 53-67.

Glucksmann, A. 1965 Cell death in normal development. Arch. Biol., 76: 419-437.
Hollyfield, J. G. 1968 Differential addition of cells to the retina in Rana pipiens tadpoles. Develop. Biol., 18: 163-179.

Johns, P. R. 1977 Growth of the adult goldfish eye - III. Source of the new retinal cells. J. Comp. Neur., 176: 343-358.

Johns, P. R., and S. S. Easter 1977 Growth of the adult goldfish eye - II. Increase in retinal cell number. J. Comp. Neur., 176: 331-342.

Kahn, A. J. 1974 An autoradiographic analysis of the time of appearance of neurons in developing chick neural retina. Develop. Biol., 38: 30-40.

Morest, D. K. 1970 The pattern of neurogenesis in the retina of the rat. Z. Anat. Entwicklungsgesch., 131: 45-67.

Müller, H. 1952 Bau and Wachstum der netzhaut des guppy (Lebistes reticulatus). Zool. Jb. (Zool. u. Physiol.), 63: $275-324$

Raviola, E., and N. B. Gilula 1973 Gap junctions between photoreceptor cells in the vertebrate retina. Proc. Nat. Acad. Sci., 70: 1677-1681.

Raviola, G, and E. Raviola 1967 Light and electron microscope observations on the inner plexiform layer of the rabbit retina. Am. J. Anat., 120; 403-426.

Sandeman, D. C., and N. R. Rosenthal 1974 Efferent axons in the fish optic nerve and their effect on the retinal ganglion cells. Brain Res., 68: 41-54.

Sidman, R. L. 1961 Histogenesis of mouse retina studied with thymidine- $\mathrm{H}^{3}$. In: The Structure of the Eye. G. K. Smelser, ed. Academic Press, New York, pp. 487-506.

Weibel, E. R. 1969 Stereological principles for morphometry in electron microscopic cytology. Int. Rev. Cytol., 26: 235-302.

Witkovsky, P. 1971 Synapses made by myelinated fibers running to teleost and elasmobranch retinas. J. Comp. Neur., 142: 205-222.

Witkovsky, P., and J. E. Dowling 1969 Synaptic relationships in the plexiform layers of carp retina. Z. Zellforsch., 100: 60-82.

Witkovsky, P., M. Shakib and H. Ripps 1974 Interreceptoral junctions in the teleost retina. Invest. Ophthalmol., 13: $996-1009$. 